\title{
Contribution to the Knowledge of the Vegetation Dynamics Processes in the Lesser Antilles
}

\author{
Philippe JOSEPH \\ Professor: Ecology, Biogeography and Botany, University of the French West Indies, UMR SPACE DEV-BIORECA
}

\begin{abstract}
The geomorphology and the climate represent the two elements that form the basis of biotope diversity in the Lesser Antilles. They are home to many plant species expressing various combinations. Irrespective of their morphogenetic phases and phytocenotic evolution stages, the taxa occupy specific sites. These sites named installation and expansion site represent volumes (epigeous and hypogeous sections) whose factorial features vary in parallel to the ecosystem changes and where the plants, based on their ecological profiles, go through the various stages of their development to reach maturity (phenology). A vegetation unit can therefore be equated with a set of interdependent installation and expansion sites corresponding to different species populations. The progressive or regressive vegetation dynamics translates into floristic preponderance changes. This fact is linked to changes in the dominance relations between the families on the installation and expansion sites. Understanding the latter is helpful to approach the auto-ecological and synecological process. Starting from scientific literature data (in particular those regarding the Caribbean), in this paper we will show the important role played by the installation and expansion sites in the spatio-temporal dynamics of the plant ecosystem.
\end{abstract}

Keywords: Lesser Antilles, Vegetation, anthropization, plant succession.

\section{Introduction}

Just like many other geographical areas, the strongly anthropized appearance of the Lesser Antilles vegetation renders understanding its restructuring means difficult [1][3]. The multiplicity of preponderant floristic groups in all the study sites is an indicator of the extreme variety of the underlying mechanisms [4]. It seems that there is no pre-set logic nor direction. The vegetation dynamics ranges within a field of possible directions depending on the initial species fund and the site history in relation to disruptive pressures (natural and/or anthropic) [5]-[8]. The species installation depends on their biological characteristics which affect their ability to adapt or fail to adapt to the environment factors. At first glance, we can consider the vegetation as acomplex interactive entity where small factor changes and behavioural differences allowthe emergence of specific species groups [9]. It is actually a set of basal units (microsites or microterritories) which form the basis of this biocenotic diversity. However, despite the intra and inter site differences (of the basal units which represent microsites), across the successional dynamics we can list the plant formations by their types, subtypes, characteristics and evolution stages[10]-[12] as the interdependence between species represents the basis of the plant structure.

The photic energy decrease in the internal environment of the vegetation cover during its evolution, in principal the forest canopy selects the specific species of the floristic potential on the ground [13]-[15]. To this we add the behaviour of taxa compared to the other ecological and anthropic factors which also operate selections [16]-[18]. For example, as we advance in the forest complexity, overall we pass from heliophilespecies to sciaphilous species[19] [10] [20]. Intermediaries must exist for the use of all the light energy levels. These facts result in a mosaic site composed of a multitude of floristic units resulting from the multiplicity of microsites representative of the biophysical factors heterogeneity[21] [22]. Due to their structures, for each floristic unit these factors represent what we call the fabric of factorial constraints, also called decisive factorial space which depends on the dynamic stage. These are determinant factorial spaces which result in the above mentioned microsites which in fact areinstallation and expansion sites undergoing the morphogenetic process of the individuals of various species. As we will discuss in this article, we will focus on the relationships between the various levels of vegetation complexity or integration at different temporal and spatial scales.

\section{Method}

The elements below are derived from international literature data as well as from our field data, our inventories and the work of other specialist researchers on the Lesser Antilles flora. These data are scattered and are based on simple experiments [23][10][2]. We have retained the following descriptors: species diversity (ecological profiles), phytocenoses, physiognomic types, architectural and structural types. This has enabled us to propose a synthesis based on the essential traits of the multiplicity of structures, functions and evolution processes of the Lesser Antilles vegetation. In general, the elements of the argument must be considered major trends.

\section{The characteristics of the installation and expansion sites}

First and foremost the installation and expansion sites are multifactorial entities. As a result, their characteristics vary with the vegetation evolution irrespective of the macroclimate specifics. They represent the smallest components of plant formation. In a certain way they are a subsystem consisting of the plant and the soil section where it has its roots and where it is located and from which it draws its nutritional resources. We have named this system "the plant-soil microsystem": permanent expression of the meso-system represented by different plant associations or by the entire unit site (Figure 1). This micro-system, critical link - cell or basal unit - of the plant structure and indicator 


\section{International Journal of Science and Research (IJSR) ISSN (Online): 2319-7064}

Index Copernicus Value (2013): 6.14 | Impact Factor (2015): 6.391

of the vegetation's overall state, fits into a spatiotemporal dynamics linked to the biology and thus to the ecology of the various taxa. In theory, all phases of plant development occur within this microsystem. From germination to the maximal expansion associated with adaptive species strategies, therefore to the occupied ecological niches [24][26]. However, the general conditions prevailing on the sites may allow the occurrence of certain phenophases (life cycle phases). For example, the germination and the beginnings of development in the form of small diameter stem before untimely death. For a plant, irrespective of its biological type, to be part of the forest structure at any time of its development, its ecology must be in covariance with the factorial characteristics of the microsystem which represents the installation and expansion site. The installation and expansion site is the counterpart ofOldeman'secotope[27][29] which is the volume occupied by the tree during its full life cycle. The requirements are very important throughout the development process [30]. At the seedling and juvenile stage, the plant is influenced by existing structuring groups. At adulthood, it will influence theother elements of the group, irrespective of their biological types, and in return if will be influenced by them. For Oldeman[28] [29], this set of ecotopes forming a complex mesh represents the structural support of the plant group (Figure 1). During their morphogenesis, through the changes in the environmental factors, the plants candidates for the structuring of the floristic unit transform their installation sites. And as such, they create new requirements in the surrounding space. Therefore, the characteristics of the installation and expansion sites change and subsequently influence the possibilities of the implementation of regeneration of the subsequent dynamic stage species (Figure 4).

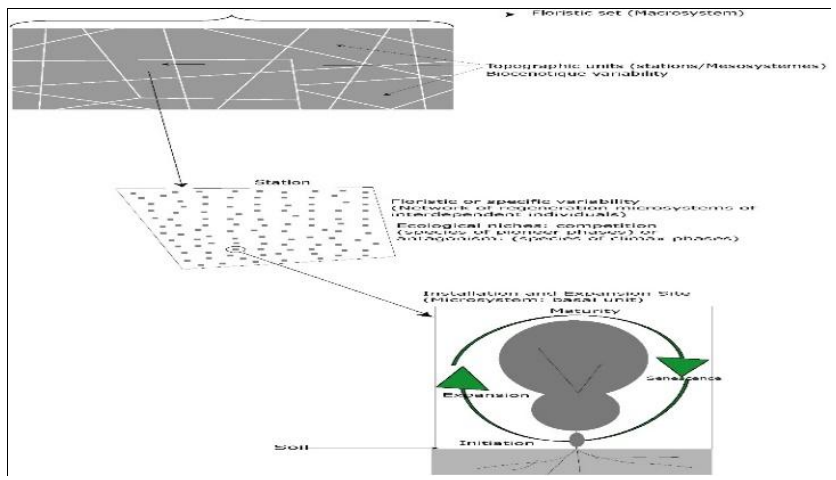

Figure 1: Example of integration levels within the ecosystem

\section{Station reality of the installation and expansion sites}

At the level of the station (meso-systeme), the sum of plant associations, the existing floristic composition is a reflection of the average identity of the installation and expansion sites (Figure 1). At each stage of the vegetation dynamics, the studied formationcan be specified by a group of ecologically dominant species. In some cases, these are different from those with the strongest phytomass. This phenomenon is widespread in our survey stations, hence the need to differentiate between the ecological preponderance, defining the environmental conditions and the biomass preponderance, which often does not fully mirror the factorial characteristics of the stations. In general, in the plant surveys, the predominant species are those with balanced populations where all age classes are represented and which are the most distributed: they occupy the majority of the installation and expansion sites because they are better adapted (Figure 2).

The preponderance (dominance) of a species or species group takes into account the number of diameter classes, the regenerations with stems of important sections involved in the main architecture of the formations. It reflects the specific characteristics of the installation and expansion sites which depend on the ecophysiology of the plant species [Their temperament or behaviour towards the environmental factors (corresponding to the ethology of animals)], on the eco-climatic conditions and on the organisation level of the vegetation cover (level of evolution). The characteristics of the intra-vegetation microclimate as well as the probability of species regeneration vary during plant succession. During a progressive dynamics, the formations that occur over time, developing their biomass, condition the decline of their own regeneration (transitional species) while ensuring the installation of new groups (future species). Long term, this process leads to the creation of extremely specific intravegetation microclimatic conditions which mainly promote the highly specialized species.

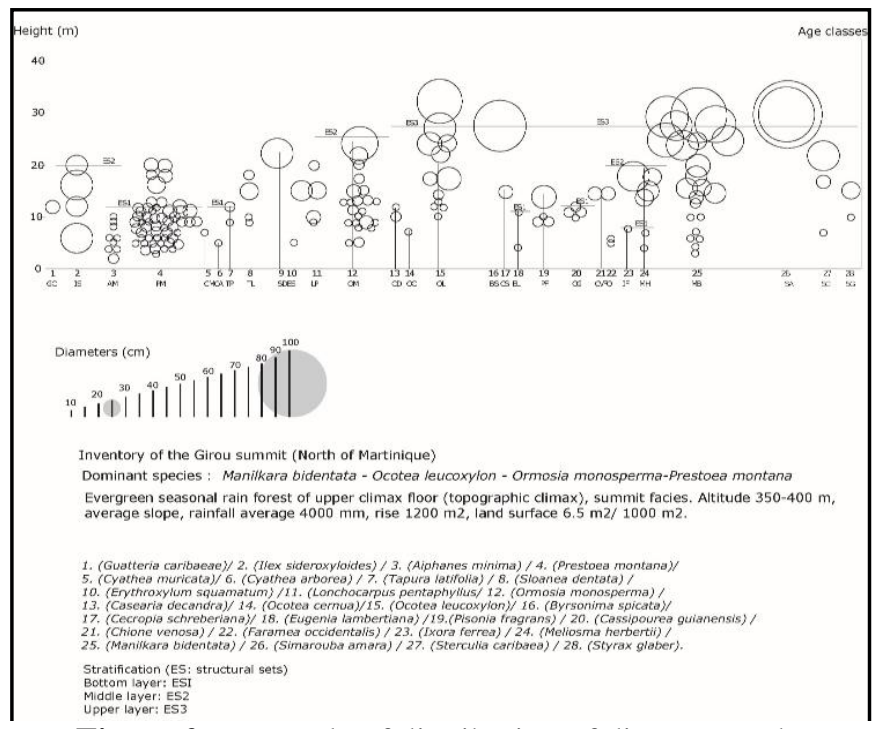

Figure 2: Example of distribution of diameter and heightclasses (population structure/forest inventory (Crete Girou - Martinique)

Generally speaking, the regressive or progressive plant dynamics results in a succession of increasingly generalist or specialized families on the installation and expansion sites. Figures $3 \mathrm{a}, \mathrm{b} \& \mathrm{c}$ respectively show the development of an individual within a schematic primary forest and a succession of species populations in the progressive evolution of two post-pioneer formations. These figures indicate a spatial and temporal variation of the installation and expansion sites. 


\section{International Journal of Science and Research (IJSR) \\ ISSN (Online): 2319-7064}

Index Copernicus Value (2013): 6.14 | Impact Factor (2015): 6.391

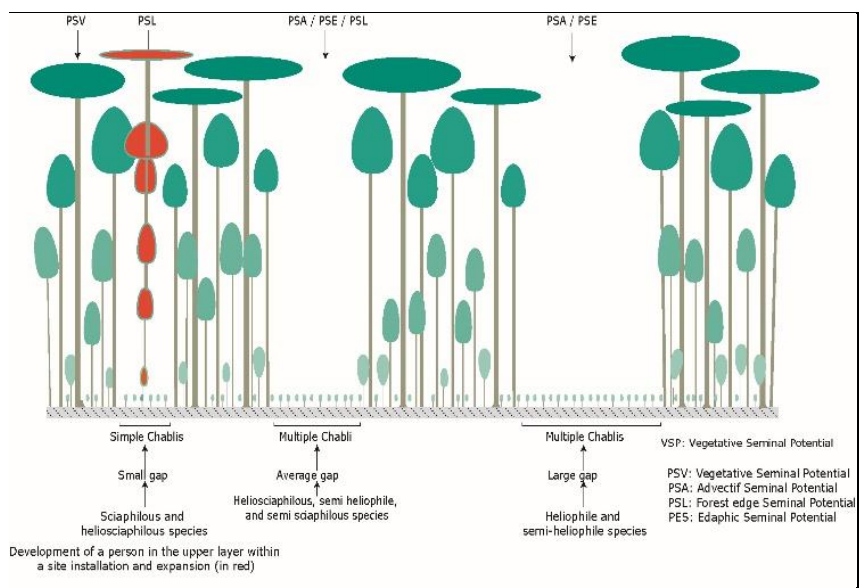

Figure 3a: Ecological profiles in the different chablis of a mature forest and example of development of an individual within an installation and expansion site

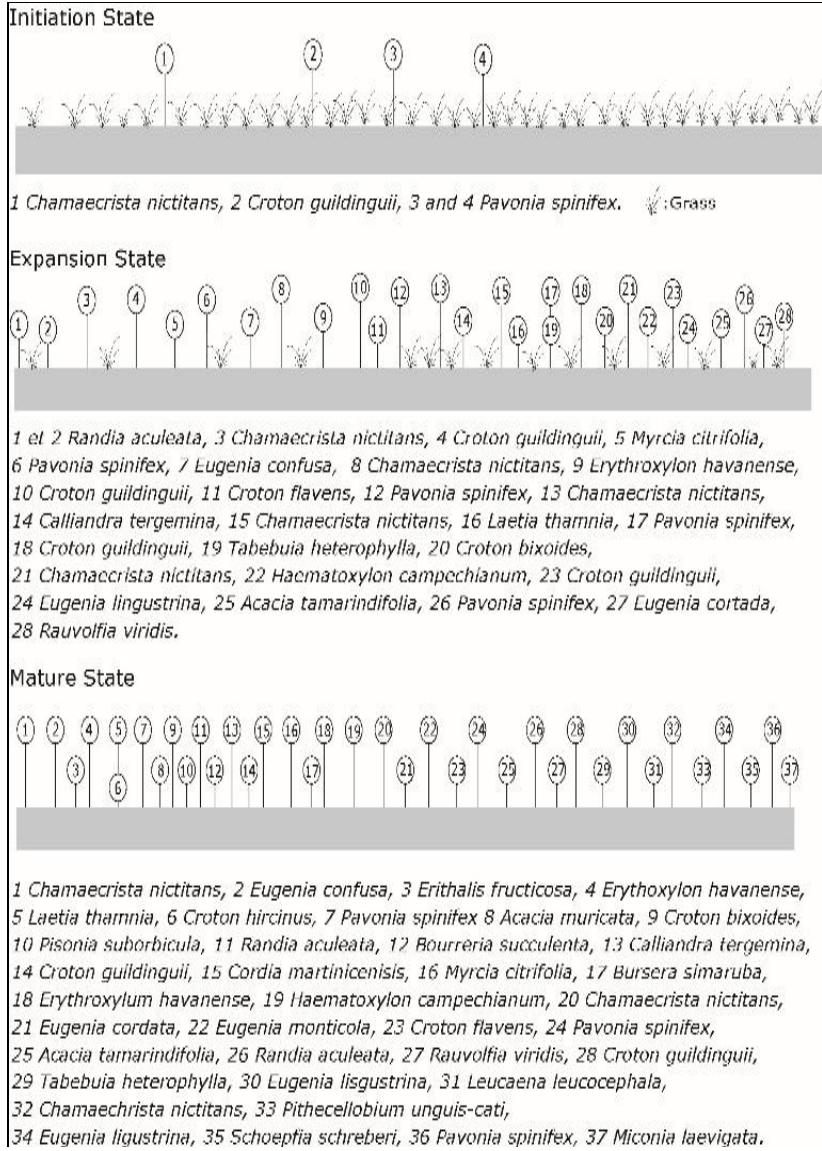

Figure 3b: Shrubs: (Lower Layer - Martinique, general synthesis)

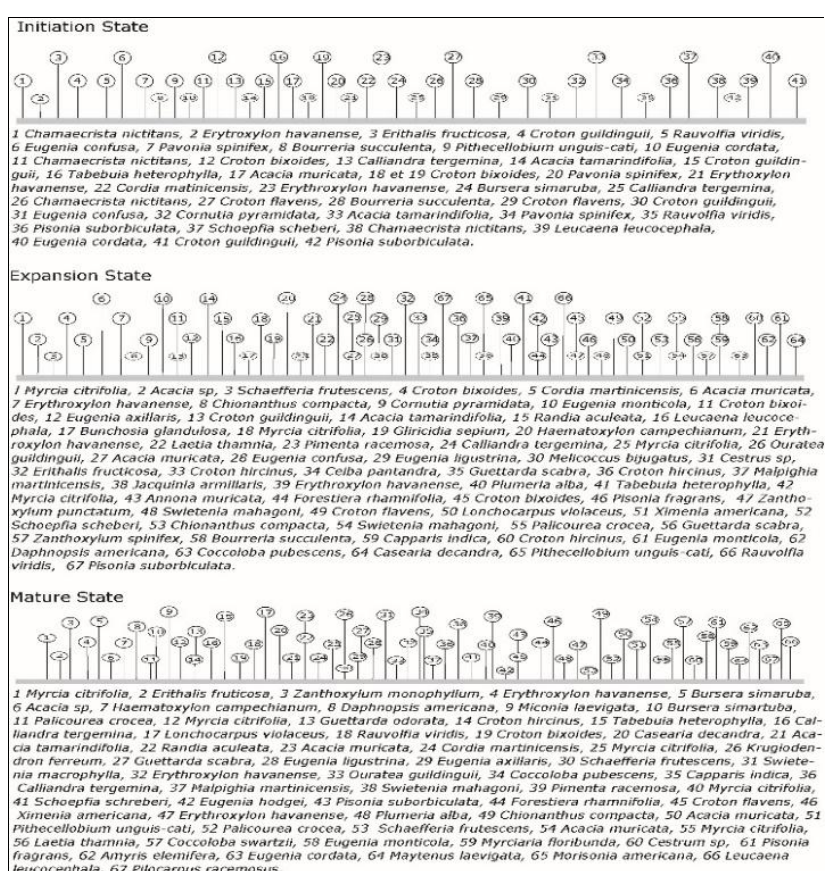

Figure 3 c: The bush formation (Lower Layer - Martinique general synthesis)

\section{Spatial distribution, evolution of the installation and expansion sites}

A forest eco-unit, or a unit from the point of view of its architecture, floristic composition and its eco-physiological functioning is conditioned by the same set of species. This group corresponds to a particular dynamic stage: the pioneer eco-unit, the post-pioneer eco-unit or the climax eco-unit with a balanced structure [Capable of all phenological phases from regeneration to maturity]. In the pioneer eco-unit the species are generalists with a significant ecological plasticity with a great capacity for wind dispersal. The diaspores have high germination efficiency. The species involved in the plant associations are "heliophile" to varying degrees, they are fast-growing and produce low density wood. We should note than the growth and densitycharacteristics are estimated compared to other species in the more advanced stages because once again everything is relative. Plant growth depends on the bioclimatic characteristics. A dry bioclimate, irrespective of the successional stages, is slower because water represents a limiting factor.

In the severely degraded areas, the installation and expansion sites exhibit a very low degree of specialization and are conquered by the species of the first wave of plant recolonization. These species have similar ecological characteristics and form the pioneer eco-units. Because the environment is open [Light interception is low] the microclimate intra-vegetation is attuned to the macroclimate [20]. At this stage, the factorial tissue generated by all the biotic and abiotic elements is not sufficiently complex so create selections due to small interspecific ecological differences. Based on all its characteristics, the pioneer ecosystem belongs to the extra-forestcycles(Figure 4). The majority of the installation and expansion sites or microsystems are occupied by species with high ecological valence. This pioneer eco-unit must be assessed in the light 


\section{International Journal of Science and Research (IJSR) \\ ISSN (Online): 2319-7064}

Index Copernicus Value (2013): 6.14 | Impact Factor (2015): 6.391

of the different aspects of its cycle marked by particular physiognomic types.

The grass formation is the most regressive and precedes other functional units. Throughout the progressive dynamics (the one that, with each stage, brings the ecosystem closer to the climax) we differentiate between: the shrubbery, the mature shrubbery, the tree, mature tree, pre-forest, structured young secondary forest, secondary forest, late secondary forest, pre-climax and climax forest phytocenoses (Figure 4). The progressive structuring of the vegetation cover is accompanied by an increase in stratification and therefore in complexity. During each phase the changes in macro-climate - and logically microclimate- factors result in transformations within the installation and expansion sites. In the discontinuous and sparse early successional vegetation cover, the different species individuals are found in a low morphological competition system which does not significantly affect their growth. The development of structuring woody heliophile species with rapid growth results in the gradual closing of the plant cover. At the same time a photic barrier is created, it slows down or cancels the development of the species located under the plant cover. Among these, some [Those that appear early in the succession and are still present in the advanced stages] will be able to resume their growth through structural changes: gaps or openings.

For species installed simultaneously, the small differences in growth form the basis of the successive waves of dominant functional groups. Actually, in this case the succession comes down to physiognomic changes. The multiple degrees of heliophiletemperament (strategic class) are paramount in the expression or marginalization of certain species. For example, regarding the photic energy, the absence of very competitive taxa can allow the emergence of heliophile plants which would normally be suppressed. This is the simple explanation of the variety of vegetation units and landscapes in the areas with a high degree of artificiality of the Lesser Antilles.

Because the mature shrub and pre-foreststructures represent the climax of the extra-forest successional cycles, the vegetation cover gradually goes through a forest process: the once pioneereco-units are replaced withpost-pioneer ecounits (Figure 4). The problem is different at this stage, the tree cover is present and its degree of closure depends on the evolution stage of the plant groups in the relevant successional cycle. The intra-forest microclimate isincreasingly out of phase withthe macroclimate (Figure 5). This is whythe intra and interspecific competition is more intense, the simple fact of belonging to an ecological group is not sufficient for installation. The greater ecosystem complexity due to a higher number of factors and the terms of their interaction acts as a selective filter affecting the biological and therefore physiological characteristics of various species (Figure 5). There is an increasingly pronounced specialization of the installation and expansion sites throughout the progressive successional cycles (Figure 5). The installed species with the potential to dominate in the future form the "future structural group". They will go through their entirephenophaseson the installation and expansion sites and at maturity they form "the existing group". Their morphological development modifies the initial characteristics of these sites (Figure 6).

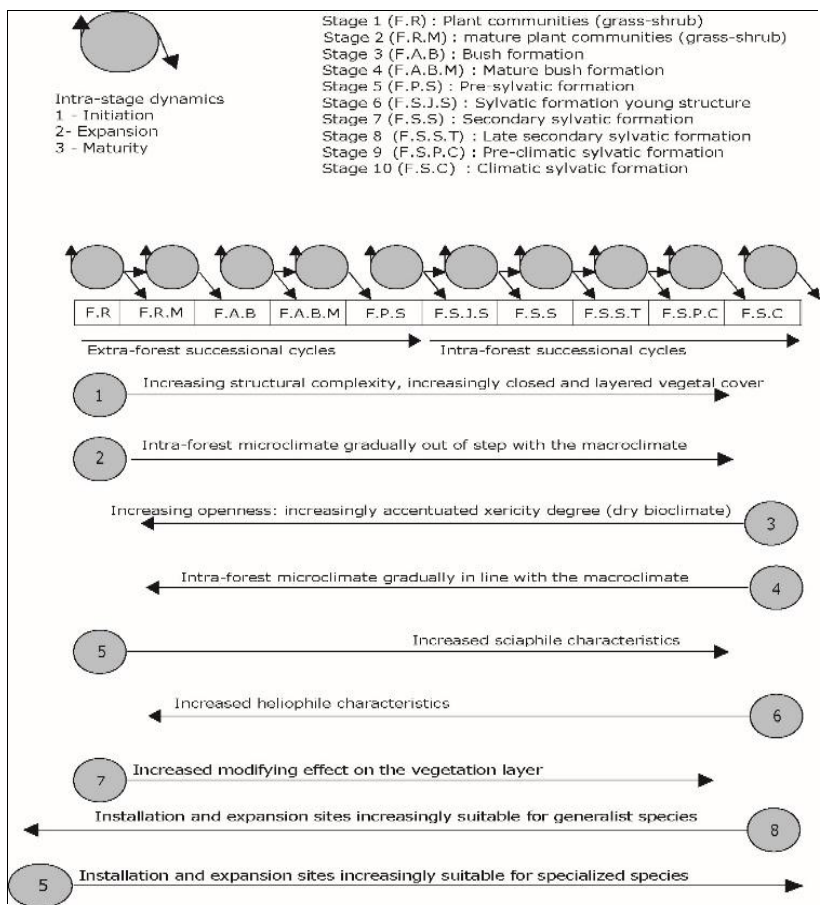

Figure 4: The different phases of plant succession
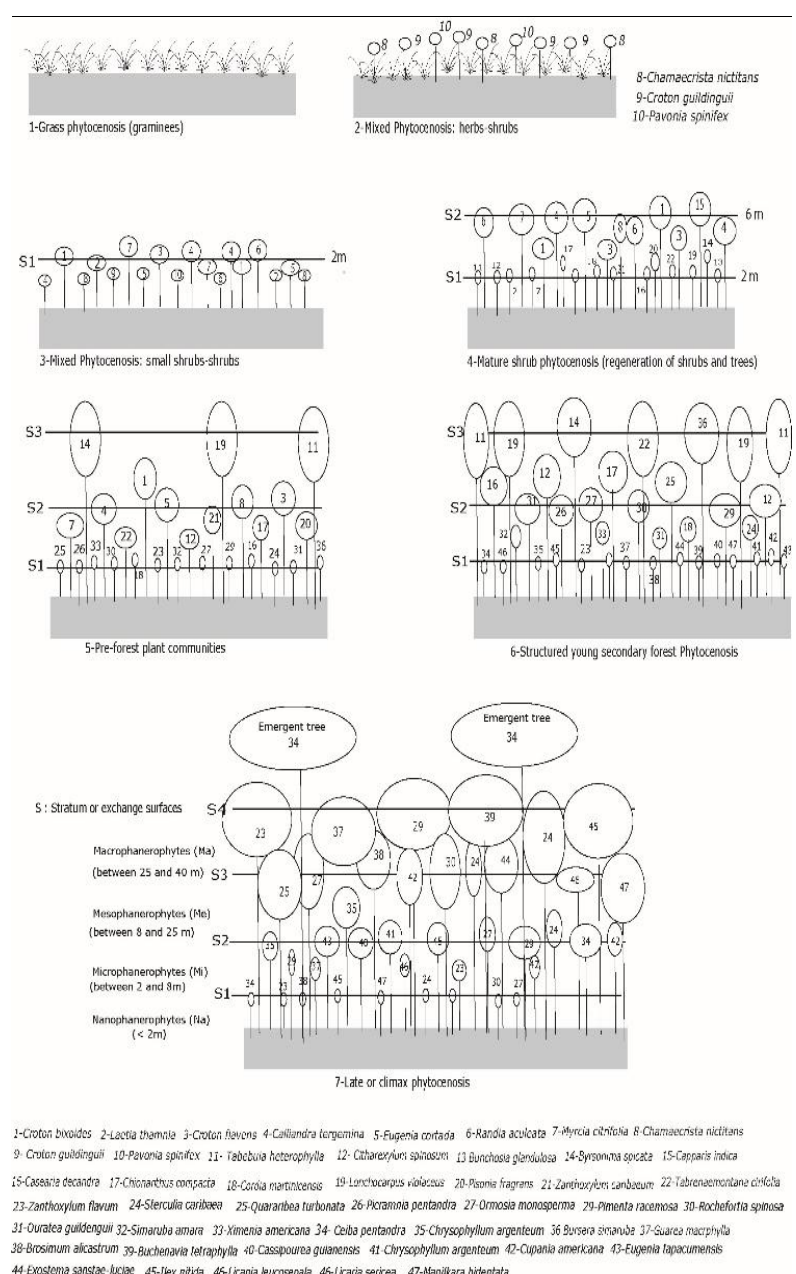

Figure 5: Schematic representation of a plausible phytocenotic succession (Martinique's low areas influenced by the drybioclimate).

\section{Volume 5 Issue 6, June 2016 www.ijsr.net}




\section{International Journal of Science and Research (IJSR)}

ISSN (Online): 2319-7064

Index Copernicus Value (2013): 6.14 | Impact Factor (2015): 6.391

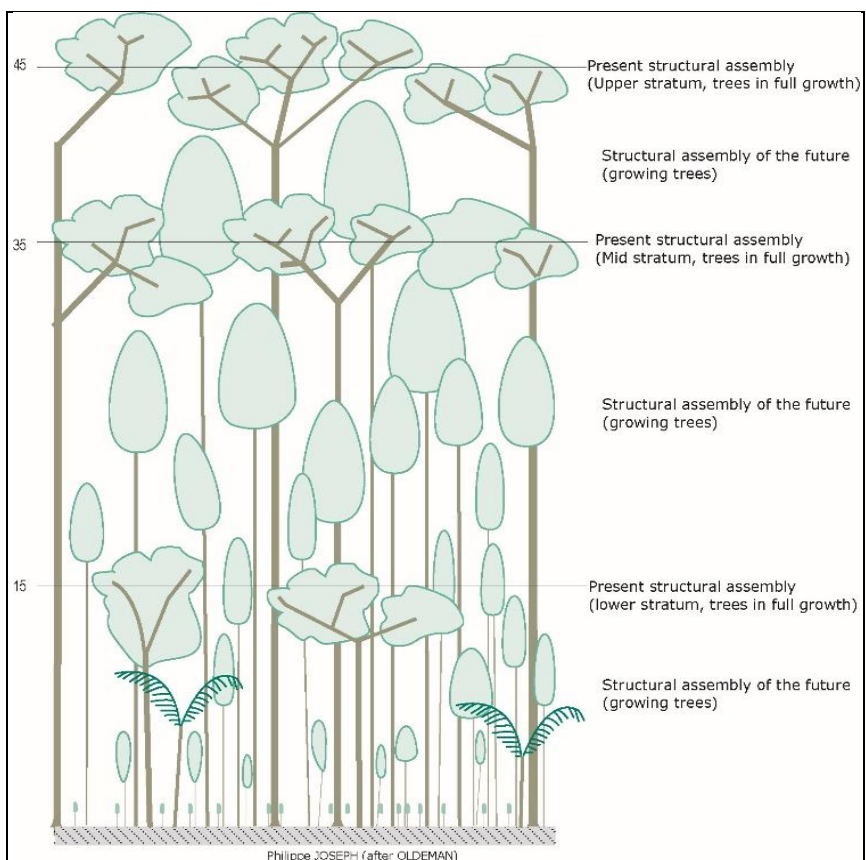

Figure 6: Schematic representation of the structural units of a climax forest

From the surface point of view, the vegetation cover in the Lesser Antilles is mainly composed of secondary or transitional species [10]. This reflects the factorial characteristics of most installation sites. The secondary stage species compared to the pioneer stage ones are less heliophile and more sensitive to bioclimatic changes. Generally speaking, the mitigation of the nychthemeral gaps of the environmental factors in the internal vegetation environment and the latter's gradual evolution are consubstantial [1].

\section{Autecological and synecological differences associated to the intra and extra-forest cycles}

Although the majority of the plant formations of these islands undergo non-forest dynamic phases, the residual forest masses allow us to understand the differences in community and individual strategies of the species which characterize these intra and extra-forest cycles. In the West Indies archipelagothe vegetation cover has forest type potential. Any profound imbalance results in functional and structural changes that affect the restoration process. When the ecological conditions ensuring a minimum of integrity are no longer met the forest ecosystem regresses until it disappears. The floristic communities which emerge are called regressive or secondary and depend on non-forest determining factors which are also called extra-forest factors (Figures $4 \& 7$ ). The recolonization often resembles the primary successional processes, when the areas are heavily damaged at floristic and soil level. Therefore a special dynamic is initiated, which begins with the occupation of the sites thus offered after the disturbances. In this case the installation sites are occupied by heliophile species and more broadly by generalist species for a large number of physical factors (Figure 8). The initial floristic composition model and the inhibition oneallow us to explain this succession mode. Thus, the evolution of the vegetation cover resulting from the expansion of the various species is the result of the expression of various biological and demographic methods: growth, biomass, reproductive rates, competition and longevity [31] [32]. For these first rank pioneers, the dynamics does not translate in the successive arrivals of species groups whose ecology is increasingly adapted to permanent changes in the environment, caused by the structural evolution of the phytocenoses. However, it is the consequence of physiognomic and even morphogenetic transformations of the existing taxa. In the installed group of plant species, those with faster growth will surpass the others and will inhibit their development as well as their own regeneration [33].

This corresponds toAlexandre'slaw of "primogeniture" [34] [35], which takes into account the chronological dimension of species installation. That is, for taxa pioneers of the globally close ecological potential, their arrival positions on the sites will determine their likelihood of future existence in the mature formations. Now we understand the importance of the dissemination vectors in plant installation. For a defined geographical area and on the same vegetation floor, this phenomenon results in a multiplicity of floristic compositions. As a result, specific natural or anthropic events will influence the associative terms of plant species both qualitatively and quantitatively. The various floristic combinations foundon-site show us that this theory is true (Figure 7).

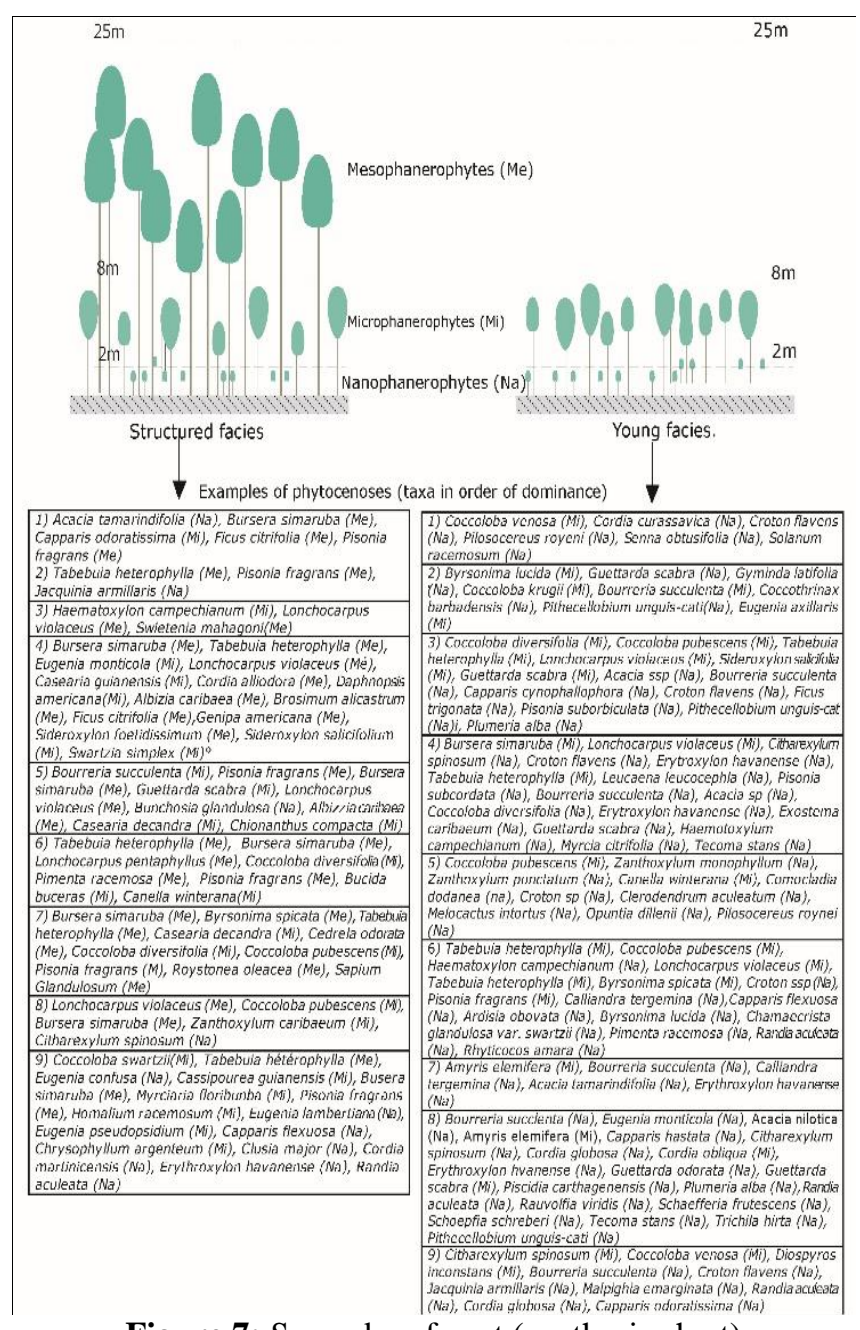

Figure 7: Secondary forest (synthesis chart)

\section{Volume 5 Issue 6, June 2016 www.ijsr.net}




\section{International Journal of Science and Research (IJSR) \\ ISSN (Online): 2319-7064}

Index Copernicus Value (2013): 6.14 | Impact Factor (2015): 6.391

After this colonization wave, in which the observable movements are physiognomic, an autogenic succession mechanism is initiated. In fact, under the guise of the mature plant unit for the relevant stage composed of first rank species (primary heliophiles), other so-called second-tier species are installed, they are a little more specialized but still heliophile in nature (secondary heliophiles). Later the secondary heliophiles will form the dominant structural groupand will eliminate the primary ones which created the ecosystem conditions necessary for their installation.

Finally, the secondary heliophiles will inhibit their own regeneration, by modifying the characteristics of their installation and expansion sites, while creating favourable conditions for the establishment of plant groups with a higher degree of specialization, including semi-heliophile or semi-sciaphilous plants. Throughout the progressive evolution of the vegetation cover and mainly for the extraforest successional phases, this "trans-successional" solidarity and inhibition processes represent the main features of the vegetation dynamics. The overall floristic potential species which will participate in the various waves of extra-forest installation are species with strong colonizing power and characterised by a high reproductive rate (" $r$ " strategy species). They support important variations in the climatic factors. The seeds are resistant to desiccation and can wait for favourable conditions to germinate.Specific variations in the eco-physiological conditions of the installation sites are needed to end the dormancy of these species and to initiate a significant germination. Frequently the diaspores need a long post-maturity period. The above mentioned mechanisms form the basis of plant succession in the extra-forest phase, from the shrubbery to the mixedpreforeststructure (Figure 6). This is not truly a long process of plant succession, they are differentiated expressions of the environmentally adapted species which occupied the installation and expansion site during the initial colonization phase.

By contrast, when the forest state exists and is sufficiently structured, the terms of vegetation dynamics change. The mature forest formation is characterised by a closed (quasicontinuous) canopy (roof or canopy) and an optimal overall biomass. On the aerial photographs of the sectors which have reached this state, we can often see a wave effect due to tree crown juxtaposition (Photo 1). This definition criterion for the developed forest communities is increasingly precise, at the time where the vegetation cover in its gradual evolution nears the final stages characterized by complex organisation formationssuch as pre-climax and climax units. Apart from the typical seasonal tropical evergreen forest and the late secondary one (advanced mesophilic one), these features are specific to all forest sets. This advanced mesophilic forest which has been only slightly modified by man frequently presents discontinuities at canopy level due to the existence of emerging heliophile or semi-heliophile trees such as the "Kapok tree" (Ceibapentandra: Bombacaceae) and the "Bois Masse" (Sapotaceae: Sainte-Lucie, unidentified). Due to its physiognomic appearance this forest type of the middle floor of some islands of the archipelago (including Martinique) resembles the tropical sub-montane forests in the plains of Equatorial America (Figure 5).
Unlike the previous ones (extra-forest phases), the intraforest phases correspond to a completely different issue. Strategically, inorder to ensure their sustainability the plant communities must adopt renewal mechanisms or very specific "turnover" mechanisms. The autogenic changes must not result in too significant differences which could endanger the stability or even the homeostasis of the forest system. The progressive structuring of the vegetation units correspondingly creates much more drastic conditions at the level of the installation and expansion sites. Therefore, the plant species must become increasingly specialized. For a forest formation we consider balanced in a sequence of the succession cycle, the vertical organisation is identifiable by means of a more or less clear stratification (Figure 5). We find it in part in the existing structural sets located on the vertical and which create a more or less stable intra-forest climate or a micro-climate (Figure 6). The variations in macro-climatic factors are buffered in the lower strata [20]. This is mainly where the crucial dynamics stages, in principal the germination, take place.

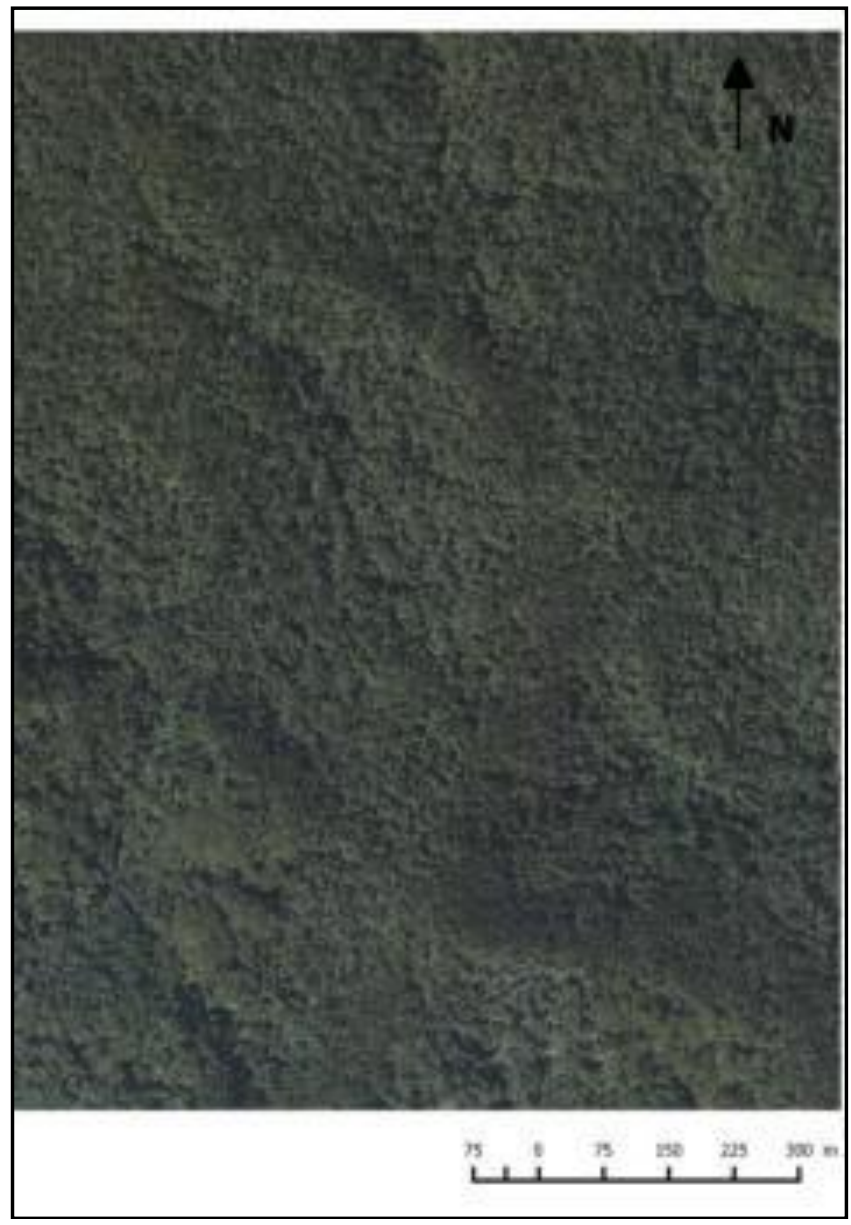

Photo 1

Volume 5 Issue 6, June 2016 www.ijsr.net 


\section{International Journal of Science and Research (IJSR) \\ ISSN (Online): 2319-7064}

Index Copernicus Value (2013): 6.14 | Impact Factor (2015): 6.391

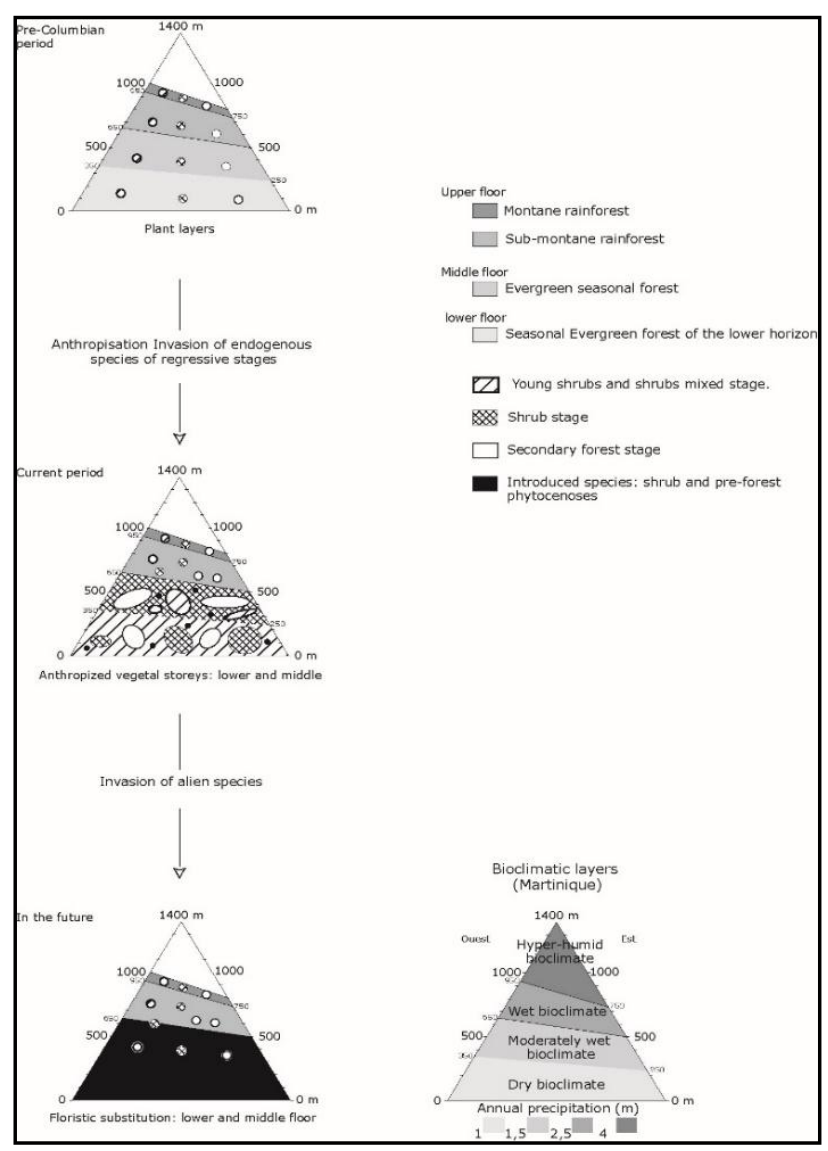

Figure 8: Evolution of Martinique's vegetation since preColumbian times

\section{The Lesser Antilles forest: a complex entity}

7.1. Two fundamental elements of the sylvigenesis: the matrix and the gap network (chablis)

In principal the forest represents a tree matrix composed of canopy species (the vegetation roof) and middle and lower strata species growing in a more or less dark or dimly lit forest understory [A twilight environment: generally at the level of the lower strata of the Lesser Antilles forest the interception is less than 7\%] (Figure 5). This image is schematic in nature and does not fully reflect the reality, as all intermediaries can be found in the forest's vertical structure. To the overall existing structure (population of maximal expansion trees, located at several stratification levels), we add representatives of the other structural groups (Figures $6 \& 9$ ): in principal the future structural groups (population of trees in full expansion) and the past structural groups (population of trees at the end of their expansion going through a senescence process). To be part of the floristic component of a mature forest ecosystem, a species exposed to environmental factors must belong to one of four strategic groups:

1) The forest sciaphilous groups

2) The scia-heliophile or helio-sciaphilous tolerant group(Joseph, 1997)

3) The group of giant anemochorous (heliophile)

4) The pioneer group (primary and secondary heliophiles) stable (temperature and humidity). The growth rate in the intra-forest microclimate is low and the changes in numbers are slow. The ultimate stages of morphological development of some trees in the upper strata require the partial opening of the canopy. The species which develop in this way become heliophile at adult age (maximal expansion). These are the representative species of the helio-sciaphilous tolerant group (Joseph, 1997), incorrectly called sciaphilous species. They have a special dynamic, because their genome carries three evolutionary advantages:

-a high ability to germinate in a closed and structured formation (complex successional stage corresponding to an intra-forest microclimate whose factors exhibit low nycthemeral and seasonal variations),

- an extremely slow seedling growth, their regeneration does not require intense photosynthetic activity (low requirement of light energy). These conditions are met in the particularly dark forest understory and this stage corresponds to the stationary phase in which species wait for structural changes in the vegetation cover to continue their expansion.

- at the end of their development, these representative species are completely heliophile in characteristics. They often need several stages to reach the final morphological expansion stage and they take place in the dominant stratum or strata. Before reaching the upper strata, the species of this family are able to tolerate the drastic lack of photic energy.Together with the pure sciaphilous species, strictly confined to the understory, the helio-sciaphilous species form the tree matrix predominant in biomass of the mature forests (old, subclimax or pre-climax and climax forests). Their renewal is mostly the result of small forest cover transformations, like the volis (the branches broken by the cyclonic winds) and the small gaps (basic chablis).

Theirtransformations in this advanced or climax forest matrix are extremely slow. Therefore the plant dynamics are part of a rather long time scale. According to the site conditions, the species join forces in floristic groups which are dominant from the point of view of their phytomass and number and are assigned a strong dominance index. In this optimal stage the presence of heliophile taxa is linked to the existence of significant changes in the forest canopy which correspond to spatial units of variable dimension: chablis or forest gaps. Unlike the matrix, the chablis occupies a very small percentage of the forest areas. It seems that the multiplicity of structures is matched by the multiplicity of functions. This concept perfectly matches Oldeman's sylvigenesis theory[28], he considers the gap as the engine of forest regeneration (Figure 9, Box 1). In fact, the sylvigenesis is not a phenomenon linked only to the forest maintenance and renewal (Oldeman, 2000). In its temporal dimension it also includes all the stages [Those which allow a space element to reach its maximum potentialwhen the conditions are met: in this case the forest] and mechanisms which lead to forest phytocenosis (Figure 4).

The trees part of the forest sciaphilous plants, or even the strict sciaphilous group, permanently occupy the forest understory and grow in sites whose ecological conditions are 


\section{International Journal of Science and Research (IJSR) ISSN (Online): 2319-7064}

Index Copernicus Value (2013): 6.14 | Impact Factor (2015): 6.391

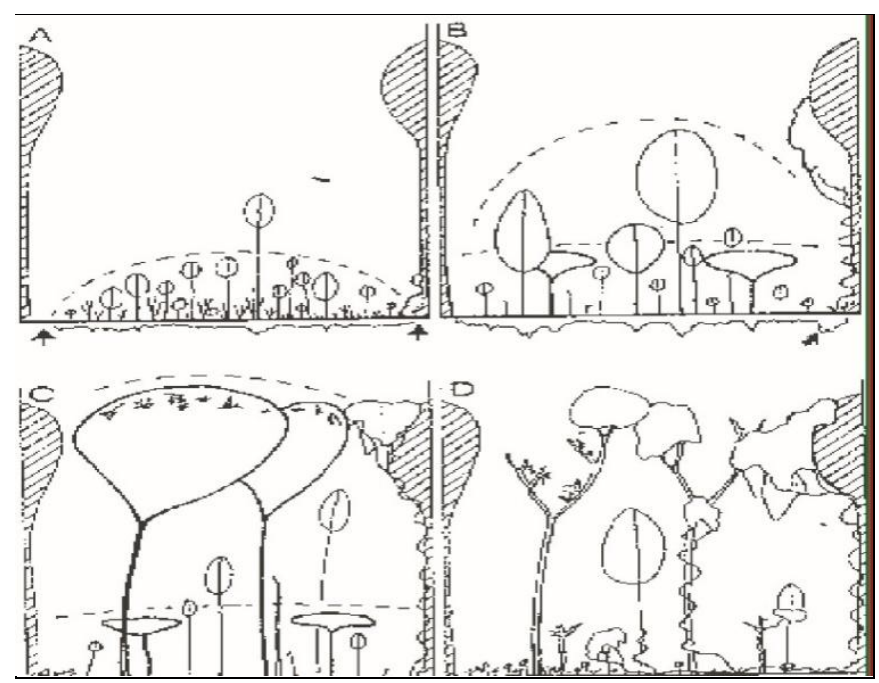

Figure 9: The four universal units of the forest mosaic (Oldeman, 1990)

\section{Box 1}

A -regeneration unit: seedlings and young trees settle in a gap caused by the fall of one or several large trees (initiation stage, Joseph, 1997);

B - aggradation unit: the growing young trees form the forest canopy (expansion stage, Joseph, 1997)

$\mathrm{C}$ - maturity unit: the dominant trees have reached their maximum size and thicken (maturity stage, Joseph, 1997)

D - degradation unit: the trees are dying and open the forest canopy again (the senescence stage).

Regarding the use of biophysical resources and each phase of the progressive succession [From extra-forest cycles to intraforest cycles], the plant ecosystem creates the conditions for the implementation of the most efficient biocenosis. In other words, the sylvigenesis does not begin with the advent of the forest entity, but its characteristics are highly influenced by earlier chrono-sequences, even the most regressive ones (Fig 4).Thus, the dynamics in its entirety is a phenomenon of unknown form with underlying mechanisms falling within different time scales (Figure 10). Taking into account the low light, the taxa of the plant matrix have a slow growth and use a variety of strategies to stay alive: they either remain inside the structure under the influence of the conditions imposed by the intra-forest micro-climate or cross all the energy barriers associated with the different strata until they settle in the canopy exposed to the regional macroclimate [14].

Conversely, the structural species having a regeneration dynamics linked to the presence of a chablis or significant damage to the forest canopy, correspond to the large representative heliophile trees like the giant anemochores [34] [35]: the heliophilecharacter of these species is expressed from the seedling stage.In the chablis (renewal unit) the architectural and floristic changes are much faster. Generally speaking, due to their strategic differences the species to be found there belong to a particular subset of the global floristic potential.If in the dominant tree matrix small changes are necessary for the growth of some scia-heliophile and helio-sciaphilousspecies without significant changes in the meso-climatic conditions with the exception of the incident energy, in the regenerating forest cells(gaps or chablis) certain microclimatic factors change significantly: light, temperature, relative humidity and evaporation. In fact, the opening of the forest cover translates into the existence of stronger vertical and horizontal gradients (edge effects) whose characteristics depend on the dimension of the damage (gaps and chablis) produced by the disturbances [15] [36]. Therefore there is a relationship between the chablis geometry and the cicatrizing floristic groups which appear, each with a specific spatial organisation. In fact, from the gap's center towards its periphery close to the matrix the species are less heliophile in nature, their growth is increasingly slow and they need a more stable environment for their development: an environment in which the factor gradients are low.

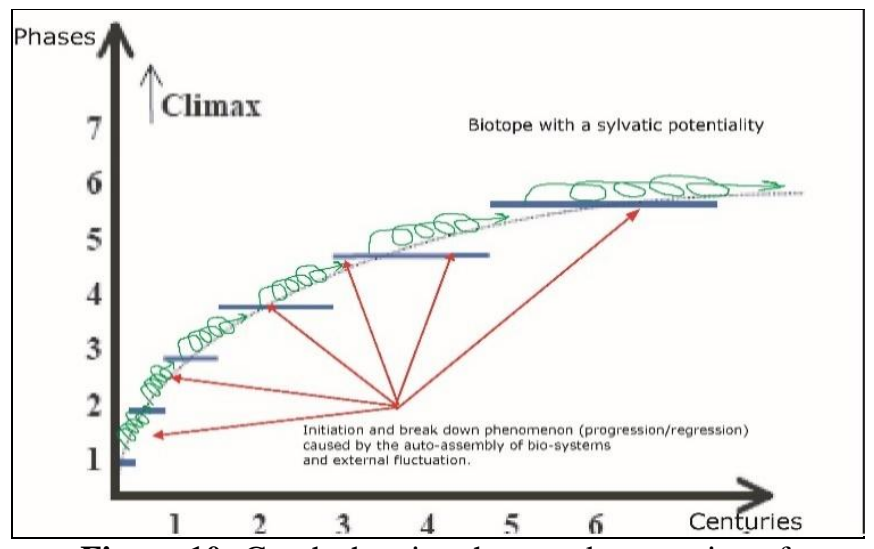

Figure 10: Graph showing the speed succession of developments phases

\subsection{Is the forest entity a super-organism ?}

At regional level, the advanced or mature forest ecosystem can be compared to a super-organism of high complexity and high dynamic stability (Figure 11)consisting of basic elements represented by the stationary behaviour species, called dryads [38]. The minor damages which are similar to injuries (chablis) endanger the integrity of the relevant system locally and initiate the healing processes by means of cicatricial or nomadic species [39] [40]. They can be durable or ephemeral. Two entities of spatio-temporal organisation oppose each other but are in constant interaction and go back to specific temporal dynamics: the forest matrix and the chablis network. Subsets of the floristic potential in which subdivisions are still possible in terms of ecological profiles are linked to these two structural and functional elements, (Figure 12). The floristic and phytocenotic differences between these two elements may be insignificant or significant and depend on the gap size and the degree of matrix complexity therefore on its level of evolution (Figure $3 a)$. The entirety of these differences in time and space result in the mosaic or "cluster"aspect of the forest formation, irrespective of its evolution stage (Figure 11). 
International Journal of Science and Research (IJSR)

ISSN (Online): 2319-7064

Index Copernicus Value (2013): 6.14 | Impact Factor (2015): 6.391

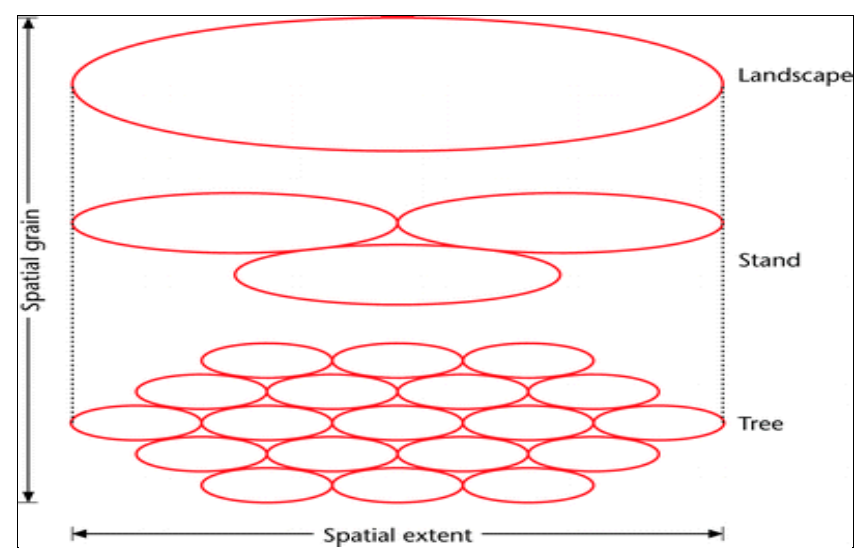

Figure 11: Conceptual model of the interrelationships between different spatial scales within the landscape hierarchy [37]

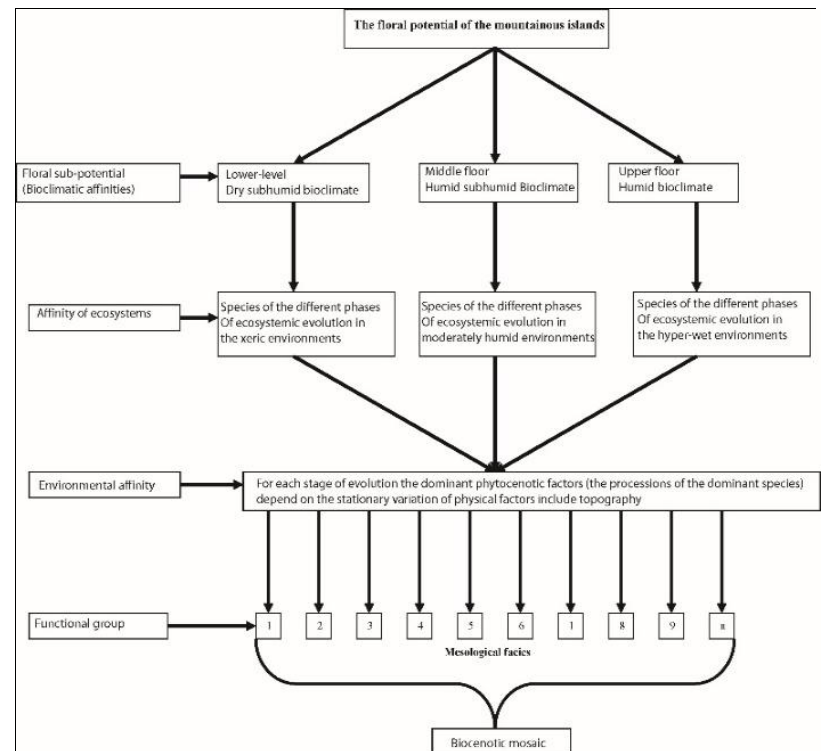

Figure 12: The various aspects of the floristic potential

Finally the strict forest pioneer group is composed of species found in the chablis of significant sizes, where the intraforest succession mechanisms are prevalent. The pioneer species are mainly present in the dynamic stages in which the extra-forest cycles succession representthe evolution engine of the vegetation cover and punctually reflect the phytocenoses like the shrubbery, the young tree or pre-forest formations or even in some cases, the young forest formations units (Figure 4).

These groups of different ecology species exhibit specific germination strategies. For the first two groups with sciaphilous regeneration, the seeds are frequently large and are equipped with important seminal reserves, which favours the zoochore dissemination. In addition, their great resistance to parasitic microorganisms is essentialfor survival inside the forest microsystem. The diaspores show no form of resistance and therefore dormancy. They are sensitive to desiccation and are suitable for germination in open spaces, especially in the "sciaphilous" forest matrix, where the internal climate factors do not undergo significant variations.

In what regards the plant species of the heliophile characterized group, their success is linked to their early arrival on the site. This is due to the fact that, for these forest heliophiles, like the schiaphilous species of the previous groups, dormancy appears to be non-existent. They are sensitive to desiccation and they must exist or be scattered before an opening can be created in order to sustaintheir populations. The beginning of their expansion and their germination phases coincide with the presence of gaps where the weather conditions are different from those of the "sciaphilous" matrix, however without being highly xeric. Apart from any resistance mechanism, these climatic conditions within the gaps are sufficient to enable the fulfilment of various biological cycles. All eco-physiological means which can be found are specific to forest species, irrespective of the fact that they belong to the "sciaphilous" matrix plant or the forest regeneration and restoration system represented by the chablis (Figure 13).

Regarding germination, the species of the pure pioneer group have an ecological strategy adapted to the territories considered open and characterised by microclimatic instabilities. One of the peculiarities of the diaspores of this group is the dormancy phenomenon which allows then to wait for favourable conditions for germination and the realization of morphogenetic processes. In reality, the diaspores are sensitive to the quality and quantity of light. Due to the phytochrome, this dormancy, is also photosensitive. In fact these seeds which are resistant to drying for a period of the year, especially in the wet subhumid and dry subhumid environments, have a particularly high colonizing efficiency. They occupy an important place in the formations whose dynamics are linked to extra-forest successional processes and can also participate in the dynamics of the large multiple chablis [anthropic or natural (cyclonic winds)].

The complexity of the forest formations operation complicates the use of a model whichcan accurately depict the plant succession in all its aspects. Moreover, the currently observable dynamic stages in these territories are specific derivatives of the primitive forest, subsequent to ancient and recent artificialization procedures. However, in a general context, we can say that a "succession system" drives the evolution of the vegetation cover. The facilitation and tolerance models are applicable for the predominant "sciaphilous" matrix, while the floristic composition of the initial and autogenic models seem more appropriate for the chablis (Figure 3a).

\section{Volume 5 Issue 6, June 2016 www.ijsr.net}


International Journal of Science and Research (IJSR)

ISSN (Online): 2319-7064

Index Copernicus Value (2013): 6.14 | Impact Factor (2015): 6.391

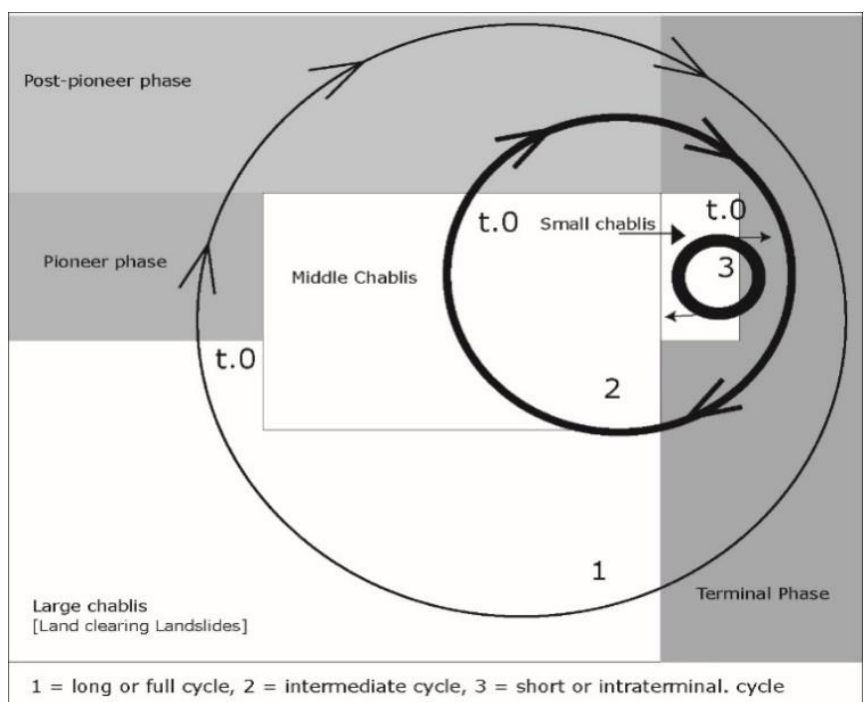

Figure 13: Sylvigenesis cycles ([41] as amended)

\section{The multifaceted nature of the floristic potential}

The floristic potential can be defined as the set of species present at a given location and for a specific period. In terms of disturbances, the history of the site determines the component of the floristic potential which will take the form of plant associations.Generally speaking, we have identified four forms of floristic potential [34] (Figure 12):

1) vegetative floristic potential, formed by plants in the vegetative state on the site.

2) thevegetative peripheral or edge floristic potential formed by the plants in the vegetative state on the periphery of the site.

3) the seminal edaphic potential (seed bank) composed of potential plant species present in the form of seeds in the soil of the site.

4) the external or advective potential consisting of plant species whose individuals are able to reproduce outside the site through dissemination vectors.

For a given site, the predominance of one potential over another depends on the degree of spatial heterogeneity of the units forming the regional mosaic, their floristic composition and the characteristics of the occurred disturbance/ disturbances. In a closed plant layer, the vegetation potential exceeds the edaphic seminal potential. In the forest sector, in the "sciaphilous" matrix the floristic potentials occur in the following order: the vegetative plant potential, the edge floristic potential and the advective floristic potential. In the gaps, the floristic potentials that will be most expressed are: the seminal edaphic potential and the advective potential. However they depend on the size of the openings and the prevailing eco-climatic conditions.

Things cannot be easily explained in the extra-forest stages, we can however clarify the specificity of the plant potential. First of all, it seems that when significant degradations occur in what regards the retention of the soil system, the seminal potential of the soil plays a very important role in the vegetal cover reconquering process. Therefore, the depletion of the seed stock of the soil system linked to direct or indirect anthropic damages is gradually represented by the predominance of the advective potential, where the success of the species depends on the mode and the dispersal vectors of their diaspores.

\section{Conclusion}

The existing vegetation of the Lesser Antilles is composed of a plural set of dynamic levels in which all structural and floristic combinations can be observed. With varying degrees, all the components of the overall floristic potential are mobilized and depend on the human history of the land plots and the adjacent ones. However, in the case of severe biotope damages, the advective and seminal edaphic potentials seem best suited to support a progressive evolution dynamics. We can hardly exceed this level of analysis taking into account the extreme heterogeneity of the spatial and temporal vegetable mosaic. As such, in the strictest sense of the term, we can state that the conditions of the "natural" plantsuccession are no longer met. The installation of anthropophyte species is one of the main consequences of the permanent environment artificialization. In other words man's actions created installation and expansion sites specific for generalist species. The latter's ecological dominance is defined by man, although they are environmentally capable of providing their full phenological cycles without his involvement. Somehow, over time, the development of human activities has resulted in the islandification of a number of forest formations, the development of regression forms (secondary phytocenoses) and even the elimination of plant species. Generally speaking, during the progressive or regressive vegetation evolution, the anthropic modifications of the original environments change the structure factors and therefore the specific or plant combinations. This results in completely different organisation and floristic composition formations than those which might occur after a natural disturbance in the absence of any previous human action. The latter was and remains a major structuring factor of the plant landscape and will have repercussions on its future developments. If the present vegetation cover will ever revert to the stage of climax forests, they would be different from those of the Amerindian period from the floristic as well as the structural and architectural point of view.

\section{Acknowledgements}

We are very grateful to the University of the West Indies (AU) and the Martinique Territorial Community (CTM) respectively for their administrative and financial contributions.

\section{References}

[1] P. Joseph, "Structure of vegetation formations and floral dynamics in the Lesser Antilles: The example of the lower vegetation level of Martinique", The Journal of Ecology (Photon 109), pp. 375-400, 2014a.

[2] A. E. Lugo, E. Medina, J. C. Trejo-Torres, E. Helmer, ЛСГ Botanical and Ecological Basis for the Resilience of Antillean Dry Forests, Neotropical Savannas and 


\section{International Journal of Science and Research (IJSR) \\ ISSN (Online): 2319-7064}

Index Copernicus Value (2013): 6.14 | Impact Factor (2015): 6.391

Seasonally Dry Forests: Plant Diversity, Biogeography and Conservation, 2006.

[3] E. Lebrija-Trejos, J. A. Meave, L. Poorter, E. A. PérezGarcía, F. Bongers, "Pathways, mechanisms and predictability of vegetation change during tropical dry forest succession", Perspectives in Plant Ecology, Evolution and Systematics, 12(4), pp. 267-275, 2010.

[4] Cano, E., A. Veloz, "Contribution to the knowledge of the plant communities of the Caribbean-Cibensean Sector in the Dominican Republic" ActaBotanicaGallica, 159(2), pp. 201-210, 2012.

[5] A.E. Lugo, E. Helmer, "Emerging forests on abandoned land: Puerto Rico's new forests" Forest Ecology and Management, 190(2), pp. 145-161, 2004.

[6] J.K. Zimmerman, M.R. Willig, L.R. Walker, W.L. Silver, "Introduction: disturbance and Caribbean ecosystems", Biotropica, pp. 414-423, 1996.

[7] C.A. Portillo-Quintero, G.A. Sánchez-Azofeifa, "Extent and conservation of tropical dry forests in the Americas", Biological Conservation,143(1), pp. 144$155,2010$.

[8] D.R. Foster, M. Fluet, E.R. Boose, "Human or natural disturbance: landscape-scale dynamics of the tropical forests of Puerto Rico" Ecological applications, 9(2), pp. 555-572, 1999.

[9] R.T. Forman, D.C. Hahn, "Spatial patterns of trees in a Caribbean semi-evergreen forest", Ecology, pp. 12681274, 1980.

[10]P. Joseph, "The vegetation of the Lesser Antilles: floristic diversity and ecosystemic dynamics" International Journal of Environmental Studies, 69(5), 816-833, 2012.

[11]M. Goede, "The dynamics of organizational change in small developing islands: the case of Curacao" Caribbean Studies, 39(1), pp. 139-167, 2011.

[12]R. Ricklefs, E. Bermingham, "The West Indies as a laboratory of biogeography and evolution" Philosophical Transactions of the Royal Society of London B: Biological Sciences, 363(1502), pp. 2393-2413, 2008.

[13] Ü. Niinemets, "A review of light interception in plant stands from leaf to canopy in different plant functional types and in species with varying shade tolerance", Ecological Research, 25(4), pp. 693-714, 2010.

[14] R.A Montgomery, R.L. Chazdon, "Forest structure, canopy architecture, and light transmittance in tropical wet forests", Ecology, 82(10), pp. 2707-2718, 2001.

[15]C. D. Canham, J.S. Denslow, W.J. Platt, J.R. Runkle, T.A. Spies, P.S. White, "Light regimes beneath closed canopies and tree-fall gaps in temperate and tropical forests" Canadian Journal of Forest Research, 20(5), pp. 620-631, 1990.

[16] C.D. Collins, R.D. Holt, B.L. Foster, "Patch size effects on plant species decline in an experimentally fragmented landscape" Ecology, 90(9), pp. 2577-2588, 2009.

[17] F. Hallé, R.A. Oldeman, P.B. Tomlinson, Opportunistic Tree Architecture, Springer Berlin Heidelberg, 1978.

[18]D. Sheil, A. Salim, J. Chave, J. Vanclay, W.D. Hawthorne, "Illumination-size relationships of 109 coexisting tropical forest tree species" Journal of Ecology, 94(2), pp. 494-507, 2006.

[19] J.P. Grime, Plant strategies, vegetation processes and ecosystem properties, John Wiley \& Sons, 2006.
[20]P. Joseph, "The Influence of Vegetation on the Main Macro-Climatic Factors: the Example of the Lower Vegetal Floor of Martinique (Lesser Antilles)", Open Journal of Botany, v.1, pp. 5-18, 2014b.

[21] M. Lohbeck, L. Poorter, H. Paz, L. Pla, M. van Breugel, M. Martínez-Ramos, F. Bongers, "Functional diversity changes during tropical forest succession", Perspectives in plant ecology, evolution and systematics, 14(2), pp. 89-96, 2012

[22] S.G. Letcher, R.L. Chazdon, "Life history traits of lianas during tropical forest succession" Biotropica, 44(6), pp 720-727, 2012.

[23]P. Joseph, Dynamique, écophysiologie végétales en bioclimat sec à la Martinique, Thèse de doctorat, Université des Antilles et de la Guyane, SeptentrionPresses universitaires, Lille (Thèse à la carte), 1997.

[24]A.T. Peterson, D.A. Vieglais, "Predicting Species Invasions Using Ecological Niche Modeling: New Approaches from Bioinformatics Attack a Pressing Problem. A new approach to ecological niche modeling, based on new tools drawn from biodiversity informatics, is applied to the challenge of predicting potential species invasions" BioScience, 51(5), pp. 363-371, 2001.

[25] J. Soberón, A.T. Peterson, "Interpretation of models of fundamental ecological niches and species distributional areas" Biodiversity Informatics 2: pp.1-10, 2005.

[26] J.M. Chase, M.A. Leibold, Ecological niches: linking classical and contemporary approaches. University of Chicago Press, 2003.

[27]R. Oldeman, Forests: elements of sylvology, SringerVerlag Edition, Berlin, 1990.

[28] R. Oldeman. L'architecture de la forêt guyanaise. Th. 3e cycle:Sci. Nat., Paris: ORSTOM, (73), 1974.

[29]R. Oldeman, "Arbres, architecture, évolution", In Colloque International sur l'arbre (4è: 2000-Montréal, Québec): L'arbre, pp. 364-374, 2000 .

[30]F. Hallé, R. Oldeman, Essai sur l'architecture et la dynamique de croissance des arbres tropicaux. (Monographie de Botanique et de Biologie Végétale, 6), Paris : Masson, 1970.

[31] J.H. Connell, R.O. Slatyer, "Mechanisms of succession in naturalcommunities and theirrole in communitystability and organization", American naturalist, pp. 1119-1144, 1977.

[32] S.T.A. Pickett, S.L. Collins, J.J. Armesto, "Models, mechanisms and pathways of succession", The Botanical Review, 53(3), pp. 335-371, 1987.

[33] S. Pickett, M.L. Cadenasso, S.J. Meiners, "Ever since Clements: from succession to vegetation dynamics and understanding to intervention", Applied Vegetation Science, 12(1), pp. 9-21, 2009.

[34] D.Y. Alexandre, Dynamique de la régénération naturelle en forêt dense de Côte d'Ivoire, Études et Thèses, Paris : ORSTOM, 1989

[35]D.Y Alexandre, "Étude de l'éclairement du sous-bois d'une forêt dense humide sempervirente (Tai, Coted'Ivoire)", Acta Oecol./Oecol. Gen. 3: pp. 407-47, 1982.

[36]F. Wittmann, J. Schöngart, W.J Junk, "Phytogeography, species diversity, community structure and dynamics of central Amazonian floodplain forests", In Amazonian floodplain forests (Springer Netherlands), pp. 61-102, 2010 . 


\section{International Journal of Science and Research (IJSR) \\ ISSN (Online): 2319-7064}

Index Copernicus Value (2013): 6.14 | Impact Factor (2015): 6.391

[37] J.A. LaGro, Landscape Ecology. In: eLS. John Wiley \& Sons Ltd, Chichester, 2001 [http://www.els.net [doi: 10.1038/npg.els.0003247]]

[38] M.D. Swaine, T.C. Whitmore, "On the definition of ecological species groups in tropical rain forests" Vegetatio, 75(1-2), pp. 81-86, 1988.

[39] M. Kellman, R. Tackaberry, "Disturbance and tree species coexistence in tropical riparian forest fragments" Global Ecology and Biogeography Letters, pp. 1-9, 1993.

[40] S.A. Schnitzer, W.P. Carson, "Tree fall gaps and the maintenance of species diversity in a tropical forest", Ecology, 82(4), pp. 913-919, 2001

[41] J.P Fiard, Les forêts du nord de la montagne Pelée et des édifices volcaniques du piton Mont-Conil et du MorneSibérie, Diplôme universitaire de phyto-écologie tropicale et aménagement insulaire, Université des Antilles et de la Guyane, 1994.

Volume 5 Issue 6, June 2016 www.ijsr.net 